\title{
DIRETRIZES PARA MANUAIS E VÍDEO TUTORIAIS DIDÁTICOS DE JOGOS ANALÓGICOS
}

\section{DIDACTIC GUIDELINES FOR TABLETOP GAME MANUALS AND VIDEO TUTORIALS}

\author{
João Léste ${ }^{1}$, Bach \\ Claudia Mont'Alvão ${ }^{2}$, D.Sc \\ (1) LEUI - PPGDesign - PUC-Rio \\ jvleste95@gmail.com \\ (2) LEUI - PPGDesign - PUC-Rio \\ cmontalvao@puc-rio.br
}

Manuais de jogos, Vídeo tutoriais, Jogos analógicos

O presente artigo visa analisar as características necessárias de manuais de jogos analógicos, de acordo com as determinações do Código de Defesa do Consumidor, além de comparar, sob a ótica da ergonomia informacional, as características dos manuais impressos - presentes em todos os jogos analógicos - e dos vídeo tutoriais relativos aos mesmos jogos.

Game manuals, Video-tutorials, Tabletop games

This article intends to analyze which characteristics tabletop game manuals ought to have in order to comply with Brazilian's Consumer Protection Codes, while comparing, from an informational ergonomics perspective, these same manuals - that need to be present in every sold game - with video tutorials about the same games.

\section{Introduçãa}

O meio dos jogos analógicos apresenta uma problemática pouco explorada até o momento no meio acadêmico, especialmente o brasileiro: a baixa qualidade de muitos dos manuais de instruções fornecidos pelas produtoras de jogos, do ponto de vista ergonômico. É de conhecimento geral que a tarefa de ler manuais não é agradável para usuários desse tipo de produto - situação que é frequentemente endereçada, seja por jogadores amadores ou por profissionais (MACKLIN, 2015) e pesquisadores da área (HAM, 2016).

Apesar dos esforços de alguns profissionais da área, a exemplo dos colaboradores do site Board Game Design $L a b^{l}$, que reúne uma série de artigos sobre diretrizes e dicas para a produção de manuais mais adequados ao público, muitos dos jogos lançados em território nacional nos últimos anos ainda tem manuais que apresentam uma série de

\footnotetext{
${ }^{1}$ Repositório disponível em https://www.boardgamedesignlab.com/rules/\#writing
}

inadequações, o que mantém a tarefa de leitura deles onerosa, corroborando com as baixas expectativas dos usuários. Isso se deve, entre outros fatores, ao fato de que não há nenhuma regulamentação por parte da legislação brasileira sobre boas práticas do projeto e da escrita de manuais, permitindo que cada empresa siga diretrizes próprias. Dessa forma, há grandes discrepâncias entre os resultados finais de manuais de diferentes tipos de jogos, empresas e regiões.

Paralelamente, está se consolidando um novo nicho de formas de ensinar e aprender as regras de jogos analógicos: os vídeo tutoriais explicativos, tanto oficiais - produzidos pela editora do jogo - quanto não oficiais - produzidos, geralmente, por influenciadores digitais desse meio.

Nesse contexto, o presente artigo visa fazer uma análise comparativa exploratória entre estes dois tipos distintos de documentos, a fim de identificar características positivas presentes nos vídeo tutoriais que possam justificar o crescimento deste nicho, além 
da possibilidade de serem adaptadas para a linguagem escrita do manual.

Primeiramente, ocorreu uma investigação sobre a disponibilidade de vídeo tutoriais em bancos de dado da internet, diferenciando-os entre oficiais e não oficiais. Em seguida, foram selecionados três jogos e, em função da análise dos vídeos e manuais disponíveis, elaborou-se tabelas comparativas, comentadas posteriormente. Segue abaixo os jogos selecionados e a justificativa da seleção:

Coup $^{2}$, jogo de cartas e blefe lançado em 2012 e nomeado para diversos prêmios. Ele se mantém popular até hoje, possibilitando que fosse importado para o Brasil, recebesse uma nova expansão, um pacote de cartas especiais (usando personagens de obras famosas de ficção como personagens do jogo) além de uma reformulação no projeto artístico das cartas - aclamado pelo público - e gráfico do manual. Por consequência, diversos canais do YouTube de produtores independentes de conteúdo dedicados ao teste, avaliação e crítica de jogos produziram vídeo tutoriais não oficiais para o Coup, apresentando um espaço amostral significativo de material de análise, tanto em inglês quanto em português;

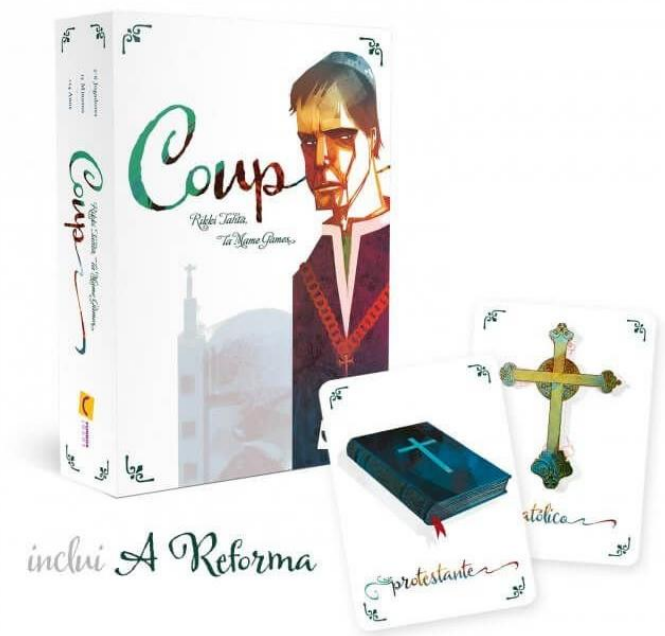

Figura 1 - Versão brasileira de Coup com expansões

Nemesis, cuja editora fez uma parceria com um canal preexistente no YouTube para produzir um extenso vídeo tutorial oficial para o jogo, o que oferece um contraponto ao jogo anterior, por ter sido produzido por pessoas envolvidas no projeto

\footnotetext{
${ }^{2}$ Versão reduzida de Coup d'État, do francês que traduzido para o português significa "Golpe de Estado" - conceito que norteia a premissa do jogo.
}

do jogo em si. Tendo sido um jogo viabilizado por financiamento coletivo, muitas das etapas de produção foram divulgadas ao público, inclusive o protótipo do manual, que será comparado posteriormente ao documento final para investigar mudanças e melhorias que possam ter ocorrido;

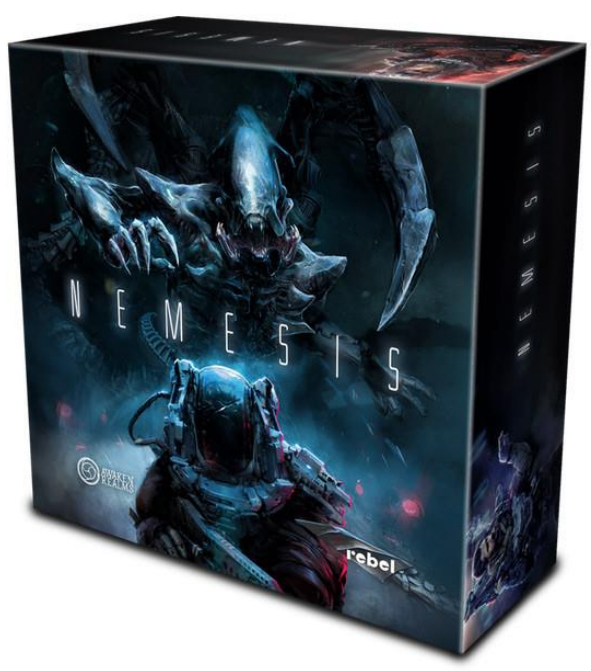

Figura 2 - Caixa do jogo base Nemesis

Santorini, cuja editora possui um canal do YouTube com vídeo tutoriais oficiais, primariamente dedicados à explicação de diferentes aspectos do jogo. A produção de vídeos curtos e complementares apresenta um contraponto interessante aos exemplos anteriores, dialogando com a proposta da campanha de financiamento do jogo: produção de expansões à medida que a empresa adquira mais capital; 


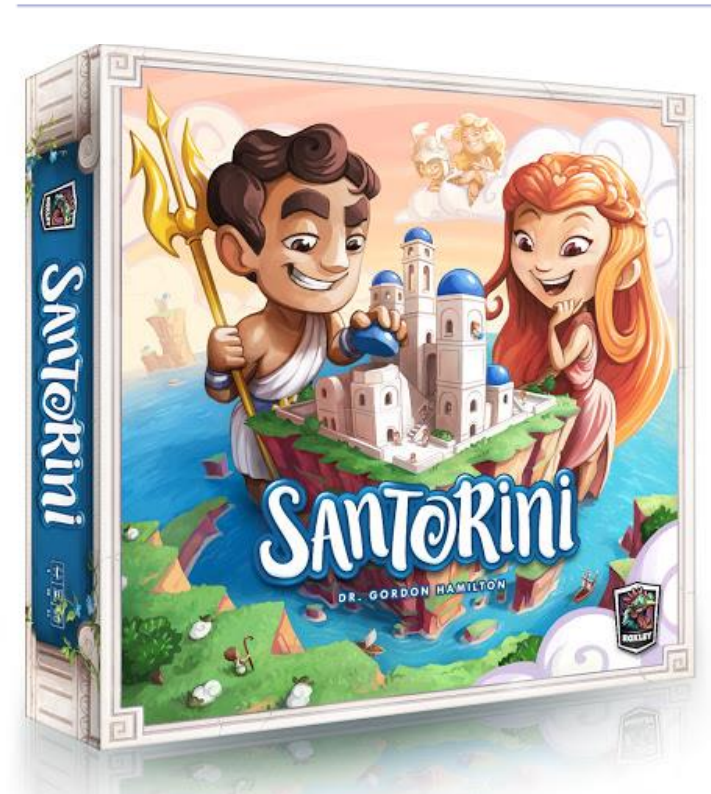

Figura 3 - Caixa do jogo base Santorini O critério de escolha para esses diferentes estilos de vídeos produzidos foi que a pluralidade de tipos de representações oferece um espaço amostral diversificado e, portanto, pertinente para uma análise comparativa e exploratória do contexto do mercado. Além disso, a investigação inicial de diferentes facetas desse nicho é o primeiro passo na identificação de qual das modalidades de vídeo é mais eficiente em complementar situações e contextos de usuários que os manuais impressos são incapazes (ou possuem extrema dificuldade) de contemplar, a exemplo de pessoas analfabetas ou pessoas cegas, conferindo mais acessibilidade ao meio dos jogos analógicos.

\section{Em Defesa da Regulamentação dos Manuais}

De acordo com a legislação brasileira, todo e qualquer produto comercializado em território nacional precisa ser acompanhado de instruções didáticas e ilustradas, adequadas ao contexto específico de uso em questão, conforme o Código de Defesa do Consumidor:

Art. 50. A garantia contratual é complementar à legal e será conferida mediante termo escrito. Parágrafo único. O termo de garantia ou equivalente deve ser padronizado e esclarecer, de maneira adequada, em que consiste a mesma garantia, bem como a forma, o prazo e o lugar em que pode ser exercitada e os ônus a cargo do consumidor, devendo ser-lhe entregue, devidamente preenchido pelo fornecedor, no ato do fornecimento, acompanhado de manual de instrução, de instalação e uso do produto em linguagem didática, com ilustrações. (CDC, 2017)

Todavia, apesar de não haver dúvidas da necessidade que qualquer jogo analógico seja acompanhado do manual de uso adequado - o manual de regras do jogo -, fica a cargo dos designers, produtores e editores interpretarem o significado de "linguagem didática, com ilustrações" ao projetarem o manual. A falta de uma definição mais precisa e regulamentada do que caracteriza a linguagem didática e de como devem ser aplicadas às imagens faz com que os manuais apresentem características altamente discrepantes, dificultando a percepção e a definição de diretrizes adequadas para os mesmos.

Analisando outros tipos de produtos, pode-se constatar que existe uma categoria no mercado que possui regras e regulamentações sobre suas instruções de uso bastante rigorosas: produtos alimentícios. Em breve observação, percebe-se que todo produto alimentício industrializado possui, em sua embalagem, as seguintes informações (no mínimo): data de fabricação e validade; ingredientes; tabela nutricional; peso líquido; avisos sobre agentes alergênicos; instruções de armazenamento; e instruções de consumo.

Naturalmente, no caso de alimentos, é imprescindível que todas as informações pertinentes estejam presentes na embalagem, visto que o consumo inadequado de alguns destes produtos pode acarretar problemas graves de saúde. Portanto, a regulamentação do tipo de informações que devem estar presentes nas embalagens ocorre "considerando que a rotulagem nutricional facilita ao consumidor conhecer as propriedades nutricionais dos alimentos, contribuindo para um consumo adequado dos mesmos;" (ANVISA, 2003).

Portanto, para que esses dois objetivos fossem atingidos, foram estabelecidas uma série de normas que definem a forma como essas informações devem ser explicitadas - a fim de que elas possam ser apreendidas e interpretadas adequadamente pelos consumidores. Nesse sentido, mesmo tendo em mente que, em vias gerais, o contato com jogos analógicos somente apresenta riscos de uso para crianças não supervisionadas, entende-se que a conclusão de que "a fim de garantir a qualidade das informações passadas para o consumidor deve-se estabelecer diretrizes sobre como essas informações serão expressadas" (ANVISA, 2003) se aplica aos manuais de jogos analógicos, visto que quaisquer possíveis riscos, 
mesmo que mínimos, devem ser devidamente informados ao consumidor, no momento da compra, e ao usuário, no momento de jogo.

Ademais, essa conclusão é corroborada pela Constituição Federal de 1988, visto que ela também garante "a educação e divulgação sobre o consumo adequado dos produtos e serviços (...)" e considera que "A oferta e apresentação de produtos ou serviços devem assegurar informações corretas, claras, precisas, ostensivas e em língua portuguesa sobre suas características, qualidades, quantidade, composição (...)". Desta forma, faz-se valer a necessidade da regulamentação de quais informações devem estar presentes nos manuais de jogos - e a forma como devem ser diagramadas, projetadas e ilustradas -, que garante os direitos de acesso à informação dos consumidores, estando de acordo com os interesses da Constituição.

\section{A Didática e a Ergonomia dos Manuais}

A leitura do manual dos jogos é um processo informativo e de aprendizado, visto que os usuários devem adquirir novas informações e inferir como aplicá-las no contexto de jogo. Dessa forma, entende-se que é necessário motivá-los a se engajar nesse processo, além de torná-lo o menos oneroso possível. Portanto, a fim de identificar as possíveis diretrizes que possam contribuir com esse caráter didático dos mesmos, foi feita uma breve pesquisa documental e bibliográfica de artigos, livros e documentos oficiais que discutem didática e processos educativos.

Durante os últimos dois anos, o Ministério da Educação coordenou a produção do Guia Digital do Programa Nacional do Livro Didático de 2020 (PNLD), que envolveu aproximadamente 100 profissionais, mais 20 deles revisores, da área de educação - e outras áreas correlatas. Nesse documento, são detalhados critérios importantes e pertinentes à seleção de materiais didáticos para serem usados no ambiente escolar. Dentre eles, vale ressaltar o trecho que explica a necessidade da contextualização do conhecimento que será aprendido:

Quais as finalidades da escola no presente? Qual o perfil de estudante que essa escola recebe? Qual formação se pretende dar a ele no espaço escolar? Preparar para o futuro ou para o presente? As perguntas admitem respostas variadas, mas todas elas acompanham a necessidade urgente de se mobilizar atividades e recursos metodológicos capazes de estimular o interesse do(a) estudante, de aguçar a criatividade e promover aprendizagens significativas. Sem aprendizagens significativas, plurais, contextualizadas, não há resposta possível a essas e outras questões concernentes à escola. (MINISTÉRIO DA EDUCAÇÃO, 2019, p. 3)

Apesar de o texto ter sido produzido para o contexto escolar, entende-se que o ponto central dos questionamentos é estabelecer que a qualidade de qualquer aprendizado depende de que o conteúdo a ser apreendido seja significativo e alinhado ao contexto de quem aprende. Nesse sentido, é evidente que uma das principais formas de tornar o aprendizado relevante é informar de antemão qual sua aplicação prática - para que ele serve - e qual seu impacto na vida de quem o aprende:

Ao iniciar uma aula, pode-se dizer: "Agora vamos aprender a respeito da valência", o que do ponto de vista da motivação não tem valor. Seria muito mais proveitoso que se informasse inicialmente o estudante que os princípios da valência o tornariam apto a compreender a composição molecular dos resultantes de reações químicas e a dominar alguns outros procedimentos realmente úteis. É evidente que, para o estudante, a chave para o motivo da realização é a concepção da ação. Ele deve querer tornar-se capaz de fazer alguma coisa. (GAGNÉ, 1973, p. 192)

Portanto, para que haja motivação, deve haver, também, um objetivo. Dessa forma, o aprendizado é o processo através do qual alguém se torna competente na realização de uma determinada tarefa, considerando "competência" como a capacidade de resolução de problemas ao acessar os conhecimentos previamente adquiridos - quando pertinentes à situação (MINISTÉRIO DA EDUCAÇÃO, 2019, p. $5)$.

Desta forma, para que este conhecimento se traduza ao contexto do aprendizado das regras de jogos analógicos, é necessário estabelecer quais os objetivos da leitura do manual e de jogar jogos. Em primeira análise, o objetivo principal desse processo parece ser simples e direto: vencer o jogo. Entretanto, o processo de transposição da teoria das regras para o contexto real do jogo é complexo, e normalmente demanda que seja feita uma partida preliminar, para testar as regras na prática e, então, compreendê-las na íntegra. Portanto, é prudente determinar objetivos menores e mais compatíveis com diferentes etapas da apreensão e compreensão das regras: 
A primeira vez quando se joga um jogo, as expectativas devem ser baixas. Jogar uma primeira partida é como fazer uma primeira panqueca: ela pode acabar mal cozida, mal formada, e geralmente é insossa em comparação com as que seguem. Quando se joga um jogo pela primeira vez, você provavelmente terá que jogar sem conseguir formar estratégias complexas ou mesmo compreender completamente as implicações das escolhas que está fazendo. Você ainda pode perceber, no decorrer do jogo, que você entendeu mal as regras desde o começo e que a primeira partida inteira do jogo foi "inútil". Para jogadores, a primeira partida (como a primeira panqueca) é um investimento na segunda. Jogadores toleram a primeira partida desajeitada e levemente desagradável na esperança que as partidas posteriores justificarão o esforço. (HAM, 2016, p. 7) ${ }^{3}$

Em função desse processo, fica evidente que um dos desafios do manual é contextualizar as regras em situações práticas de jogo, permitindo que os usuários compreendam a forma como podem - e, mais importante, devem - ser aplicadas. Tendo isso em mente, é importante relembrar da determinação do Código de Defesa do Consumidor sobre a necessidade do uso de imagens ilustrativas nos manuais de qualquer produto.

Entretanto, considerando que o Código não explicita a forma como essas imagens devem ser aplicadas, faz-se referência ao Edital de Convocação de 2018 da Coordenação-Geral dos Programas do Livro (CGPLI), que estabeleceu que os livros didáticos devem utilizar ilustrações que dialogam com o texto, considerando que "A proposta didático-pedagógica de uma obra deve traduzir-se em projeto gráfico-editorial compatível com suas opções teórico-metodológicas, considerando-se, dentre outros aspectos, a faixa etária e o nível de escolaridade a que se destina." (CGPLI, 2020, p.10)

Esse posicionamento é apoiado pelo texto de Macklin (2015), que caracteriza os recursos gráficos dos manuais como canais de contextualização da informação não triviais e pelo

\footnotetext{
3 Tradução livre de: The first time you play a game, expectations should be low. The first game is like the first pancake-it can be half-cooked, malformed, and generally pales in comparison to what follows. When you play a game for the first time, you will likely have to play without being able to form a larger strategy or
}

artigo de Tufte (2001), que defende que imagens, tabelas e gráficos devem ser apresentados próximos dos textos que fazem referência a eles, de modo que o fluxo de leitura não seja interrompido e as informações possam ser devidamente interpretadas. Ainda de acordo com o autor, sacrificar o fluxo de leitura em prol de especificações de produção fere a usabilidade textual, portanto entende-se que é necessário adotar diretrizes para os manuais "com ênfase para a lógica de utilização em vez da lógica de funcionamento" (MORAES, 2003, p. 2).

Na prática, esses direcionamentos foram incorporados na dissertação de Duarte (2015) para a Universidade Federal do Paraná (UFPR), visto que foi compreendido pelo autor - e aprovado Colegiado de Representação Discente do PPGDesign da UFPR que esta proposta de diagramação de fato torna as informações mais contextualizadas, facilitando a compreensão dos leitores:

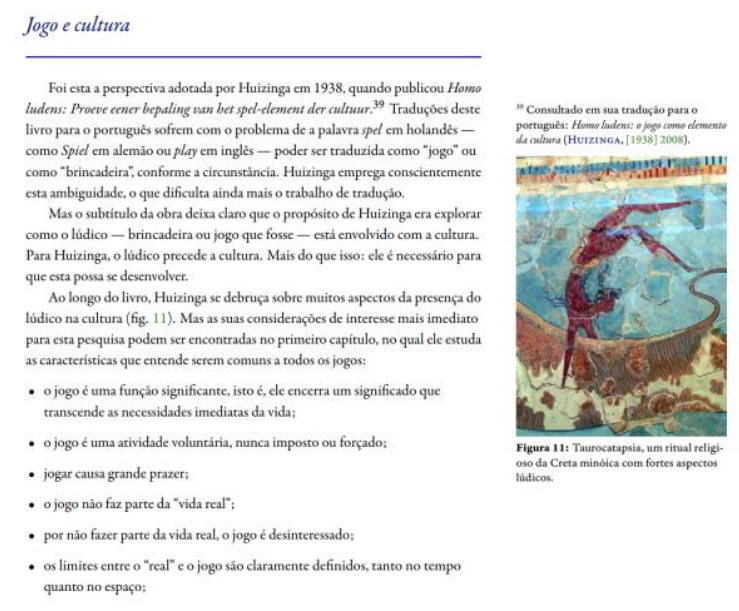

Figura 4 - Excerto da dissertação de Duarte (2015) exemplificando o uso de imagens ilustrativas, p.12

Já no contexto dos jogos de tabuleiro, alguns manuais já apresentam imagens contextualizadoras. Entretanto, elas estão majoritariamente presentes nas seções onde está sendo explicada a montagem do tabuleiro (se houver) e a preparação da partida de jogo geralmente, nas primeiras páginas. No decorrer do texto, quando algum exemplo prático precisa ser

even fully understand the implications of the choices you are making. You may even realize late in the game that you have misunderstood the rules all along and that the entire play session was "pointless." For game players, the first game (like the first pancake) is an investment in the second one. Players put up with the clunky, slightly unpleasant first game in hopes that the later games will justify the effort. 
apresentado, isto costuma ocorrer com texto corrido, escrito por extenso.

Sobre a questão da ordem das informações, também é importante levar em consideração o contexto em que elas devem aparecer (MACKLIN, 2015). No texto, o autor define clara e diretamente que um dos parâmetros de contextualização das informações dentro de uma categoria é se ela, de fato, faz parte dessa categoria: na seção sobre "preparação da partida", não é prudente se aprofundar em "ações dos jogadores", por mais que qualquer informação pertinente possa ser mencionada brevemente, caso necessário. Ademais, para estabelecer o parâmetro para a organização das categorias e seções do manual, faz-se um paralelo com o texto de Broadbent:

A compreensão é melhor se a sequência de palavras corresponde à sequência temporal dos eventos (CLARK, 1971). Portanto, espera-se que se as partes de uma máquina se encontram uma após a outra, pode ser melhor que as instruções mencionem a parte que se encontre antes, mesmo que isso signifique colocar a frase na forma passiva. $\left(\right.$ BROADBENT, 1977, p. 16) ${ }^{4}$

$\mathrm{O}$ autor conclui que, apesar das frases nas formas ativa, passiva e negativa apresentarem lógicas semelhantes, a decisão de qual das versões será utilizada não deve se basear em determinações arbitrárias e teóricas, mas no contexto do usuário que deve interpretá-las. Portanto, na situação em que o jogador deve se tornar capaz de aprender as regras do jogo - que, na maioria dos casos, devem ser aplicadas em ordens específicas -, a forma mais simples de se adequar a ela é apresentando cada uma das categorias de informações na ordem em que elas de fato aparecem e acontecem no jogo.

No artigo "A Closer Look at the (Rule-) Books: Framings and Paratexts in Tabletop Role-playing Games $^{\prime \prime 5}$ (JARA, 2011), o autor explica que um importante elemento na compreensão de qualquer texto é o pode ser chamado de Framing 6 (WOLF, 2006: 5) ou de Paratexto (GENETTE, 1997):

\footnotetext{
${ }^{4}$ Tradução Livre de "Understanding is better if the sequence of words in the sentence corresponds to the sequence of events in time (Clark, 1971). One can expect therefore that if the parts of some machine are encountered one after another, that it may be better for the instructions to mention first that part which is encountered first, even though this means putting the sentence in the passive."
}

elementos complementares ao texto cuja raison d'être ${ }^{7}$ é auxiliar no processo de leitura, imersão e interpretação do texto. Eles são múltiplos e variados, incluindo a capa do texto, título, ilustrações, notas de rodapé, comentários e - especialmente - prefácio. Esses elementos precisam estar alinhados com o objetivo da leitura visto que ele está intimamente ligado com a forma e a qualidade do processo de leitura (UNGER, 2003). Dessa forma, no momento do primeiro contato com o manual, o objetivo da leitura deve ser a introdução do usuário às mecânicas, temáticas e regras, visto que estas são as condições essenciais para que o jogo ocorra tranquilamente:

Por sua vez, estas regras são um fator muito importante para o conceito de jogo. Todo jogo tem suas regras. São estas que determinam aquilo que "vale" dentro do mundo temporário por ele circunscrito. As regras de todos os jogos são absolutas e não permitem discussão. Uma vez, de passagem, Paul Valéry exprimiu uma ideia das mais importantes: "No que diz respeito às regras de um jogo, nenhum ceticismo é possível, pois o princípio no qual elas assentam é uma verdade apresentada como inabalável". E não há dúvida de que a desobediência às regras implica a derrocada do mundo do jogo. O jogo acaba: o apito do árbitro quebra o feitiço e a vida "real" recomeça. (HUIZINGA, 2014, p. 14).

Huizinga explica, em suas palavras, um processo de Suspensão de Descrença proporcionado para o usuários pelo jogo, por meio do qual eles aceitam temporariamente a verossimilhança interna dele (LÉSTE, MONT'ALVÃO, CARVALHO, 2019). Portanto, no meio dos jogos de tabuleiro, o prefácio equivale ao elemento que permite a imersão dos usuários no "mundo" do jogo, que pode-se chamar de "contexto temático" ou "introdução" - que, apesar de não fazer parte oficial das regras, explica o funcionamento da lógica interna do jogo e do universo, muitas vezes fictício e fantasioso, onde ele se passa.

De acordo com Jara (2011), esta é uma prática comum em manuais de Role Playing Games (RPGs), e a análise deles indica que a presença desse elemento

${ }^{5}$ Um Olhar Mais Atento aos Livros (Guias): Molduras e Paratextos em Jogos Analógicos de Interpretação de Personagens. (Tradução Livre)

${ }^{6}$ Moldura (Tradução Literal), porém ela não traduz o significado exato, tendo-se mantido o termo.

7 "Razão de Ser" (Tradução Literal), questão filosófica ou ideológica que confere significado a algo. 
introdutório anterior ao texto que explica as regras do jogo, porém dentro do mesmo livro, faz com que ele seja percebido como complementar à diegese do jogo, ao passo que existe fora dela. Portanto, ela serve ao propósito de contextualizar as ações e decisões que serão tomadas no jogo, traduzindo-as para o usuário e, portanto, conferindo-lhes significado real.

Outro paratexto importante, já presente em diversos manuais, é um glossário informativo sobre termos específicos que estejam associados à temática do jogo, muitas vezes não sendo de uso comum ou possuindo significados variantes das definições de dicionários $-\mathrm{e}$, por vezes, até tendo sido inventados especificamente para o jogo. Normalmente, eles estão presentes no começo ou no final dos manuais, porém, considerando que fazem parte do processo de familiarização dos jogadores com termos importantes para o contexto do jogo, recomenda-se neste artigo que estejam presentes preferencialmente no começo.

\subsection{Diretrizes Preliminares}

A partir dos autores e documentos citados, definiram-se as seguintes diretrizes e guidelines, que devem estar organizadas na ordem em que estão apresentadas a seguir:

1) O texto do manual deve ser precedido de um paratexto introdutório que explique o universo do jogo, além de suas leis de funcionamento interno: equivalente ao prefácio de um livro, para os jogos é o Contexto Temático, ou Introdução - que pode mencionar o objetivo do jogo, se o fizer de maneira breve;

2) Caso necessário, outro paratexto a ser introduzido é o Glossário, que define sucintamente o significado de termos chave para o jogo que, se não explicados, possam gerar algum tipo de desentendimento ou falha de interpretação. Termos técnicos, a exemplo de "Turno" ou "Rodada", podem ser explicados também;

3) A fim de significar o aprendizado das regras para o contexto do usuário, é necessário informar o que ele deve se tornar capaz de fazer ao final da apreensão das regras: neste caso, informar o Objetivo do Jogo. Porém, é importante frisar que o objetivo nunca deve ser genérico, a exemplo de "vencer o jogo", visto que isto não informa o jogador sobre habilidades que desenvolverá;
4) Após os paratextos e objetivo do jogo, deve-se introduzir as regras do jogo, que devem estar organizadas na mesma ordem cronológica em que serão relevantes no jogo. Naturalmente, cada jogo possui mecânicas, componentes e regras únicas, fazendo com que essa etapa seja extremamente variável para cada caso. Entretanto, recomenda-se que a primeira das seções do manual a ser introduzida seja o Preparo do Jogo, visto que todo jogo precisa começar a partir de um estado inicial. Esse preparo pode variar desde a montagem de um tabuleiro até a quantidade de cartas que cada participante recebe, dependendo do jogo. Em seguida, deve-se introduzir as demais informações, respeitando a ordem das ações que serão desempenhadas pelos jogadores, terminando com os eventos que causam o Final do Jogo e em seguida a forma de determinar quem vence a partida (Contagem de Pontos, Desempate etc);

\section{5) Sempre que pertinente, devem ser usadas Figuras}

Ilustrativas que facilitem a compreensão das informações sendo apresentadas. Essas figuras devem estar próximas do conteúdo ao qual se referem, respeitando o fluxo de leitura natural do usuário. Ademais, recomenda-se que no mínimo os seguintes conteúdos sejam ilustrados: Preparo do Jogo demonstrando o estado inicial da mesa de jogo; Exemplos Práticos, demonstrando o estado do jogo antes e depois de ações ou eventos sendo exemplificados; e Exemplos de Componentes, da primeira vez que forem mencionados nas regras (da primeira vez que uma carta seja mencionada, um exemplo de carta deve estar presente ao lado).

Em função das diretrizes definidas acima, foram analisados os manuais e video tutoriais referentes ao jogos mencionados na Introdução, a fim de salientar se esses documentos estão em conformidade com as referências selecionadas.

\section{Análise Exploratória dos Manuais e Vídeo Tutoriais}

Considerando que a imagem ajuda a contextualizar as informações textuais-verbais, os vídeos possuem mais capacidade de ilustrar cenários práticos de jogabilidade e mecânica do jogo, além do funcionamento e interação com componentes, visto que o texto verbal é traduzido para o canal auditivo, enquanto o canal visual oferece estímulos dos efeitos dessas informações no tabuleiro e demais partes do jogo. Além disso, os vídeos contribuem para a acessibilidade parcial dos usuários cegos - visto que a explicação é oferecida auditivamente - ao passo que 
são os mais acessíveis das opções disponíveis para os usuários analfabetos, considerando que há uma série de barreiras à interação com o documento escrito.

Por outro lado, para assistir vídeos publicados no YouTube é necessário acesso à internet - o que nem sempre será possível nem fará parte da realidade dos usuários, especialmente no Brasil. Ademais, em se tratando de vídeos, só é possível apreender as informações linearmente - seguindo o fluxo cronológico do vídeo -, enquanto a manipulação da minutagem do vídeo é difícil e depende de destreza, especialmente em telas de celular. O manual, por contraste, pode ser folheado sem problemas graves, geralmente possuindo títulos para cada seção e, quando muito extensos, índices, facilitando a busca por informações.

Em seguida, foram avaliados tanto os manuais quanto os vídeos encontrados para os jogos selecionados, comparando-se as características básicas de documentos que visam apresentar informações para usuários: idioma, tipo de linguagem, tamanho, presença de indexação ${ }^{8}$, e escolha da ordem das informações.

\subsection{Coup-editora Mandala Jogos}

Foram analisados todos os manuais presentes na versão brasileira do jogo, além dos vídeos considerados como mais relevantes pela ferramenta de busca do YouTube. Pelo caráter não oficial e opinativo de alguns dos vídeos, eles apresentam pouco rigor técnico, por vezes cometendo equívocos sobre algumas regras - ou até mesmo não as mencionando.

Além disso, é importante considerar que Coup é um jogo que foi lançado em diversos países e idiomas, além de ter recebido algumas expansões ao longo dos anos. Essa situação faz com que muitos dos vídeos lançados enderecem somente as regras da versão base do jogo, que eram as únicas que existiam no momento da gravação dos mesmos, visto que o processo de regravar, re-editar e publicar novamente vídeos é muito mais complicado do que lançar um novo manual na próxima edição do jogo.

Em alguns deles, ainda, são feitas algumas piadas, comentários não relativos diretamente às regras, ou promoção de outros produtos, e, na maioria, o tempo de gameplay era muito mais extenso do que o tempo gasto com a explicação das regras.

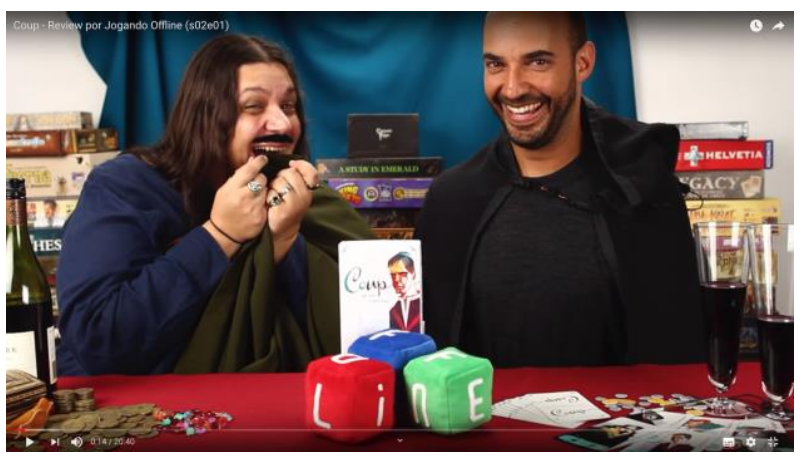

Figura 5 - Captura de tela do vídeo tutorial sobre o jogo Coup publicado pelo canal "Jogando Offline"

Além disso, nem sempre parece haver um roteiro sendo seguido à risca, o que é indicado pela interrupção da explicação de algumas informações específicas - que são retomadas posteriormente. Nesses casos, a situação foi indicada na tabela a seguir com a repetição do nome da categoria de informação seguida por "/2", considerando que nenhuma explicação foi interrompida mais de uma vez, para carecer de uma terceira parte.

\footnotetext{
${ }^{8}$ O YouTube possibilita a Marcação de Tempo (Time Stamps) nas descrições das páginas dos vídeos, que serão consideradas as indexações dos vídeos avaliados.
} 


\begin{tabular}{|c|c|c|c|c|}
\hline \multicolumn{5}{|c|}{ Vídeo Tutoriais Coup (Nomes dos Canais) } \\
\hline Rafael Studart * & Jack Explicador * & Jogando Offline * & \multicolumn{2}{|c|}{ Romir Playhouse } \\
\hline \multicolumn{5}{|c|}{ Ficha Técnica } \\
\hline Português & Português & Português & \multicolumn{2}{|c|}{ Português } \\
\hline Sem Time Stamp & Sem Time Stamp & Sem Time Stamp & \multicolumn{2}{|c|}{ Com Time Stamp } \\
\hline $25^{\prime} 21^{\prime \prime}$ & $33^{\prime} 51^{\prime \prime}$ & $20^{\prime} 40^{\prime \prime}$ & \multicolumn{2}{|c|}{$19 ' 04^{\prime \prime}$} \\
\hline Misto & Opinativo/Comentado & Opinativo/Comentado & \multicolumn{2}{|c|}{ Técnico/Não Oficial } \\
\hline \multicolumn{5}{|c|}{ Ordem das Informações } \\
\hline 1) Contexto & 1) Ficha Técnica & 1) Contexto & 1) Contexto & 2) Componentes \\
\hline 2) Ficha Técnica & 2) Preparação* & 2) Objetivo & 3) Preparação & 4) Objetivo \\
\hline 3) Objetivo & 3) Turnos & 3) Ficha técnica & 5) Preparação/2 & 6) Ações \\
\hline 4) Preparação & 4) Ações & 4) Avaliação Pessoal & 7) Ações Gerais & 8) Ação Obrigatória \\
\hline 5) Cartas* & 5) Ações Gerais & 5) Preparação* & 9) Ações de Personagem & 10) Contestação \\
\hline $\begin{array}{l}\text { 6) Ações de } \\
\text { Personagem }\end{array}$ & 6) Contestação & 6) Cartas & $\begin{array}{c}\text { 11) Ações de } \\
\text { Personagem/2 }\end{array}$ & $\begin{array}{c}\text { 12) Interação entre } \\
\text { Regras }\end{array}$ \\
\hline 7) Ações & 7) Objetivo & 7) Ações & 13) Exemplo (Explicação) & 14) Dica de personagem \\
\hline 8) Ações Gerais & $\begin{array}{l}\text { 8) Ações de } \\
\text { Personagem }\end{array}$ & 8) Ações de Personagem & 15) Final do Jogo & $\begin{array}{l}\text { 16) Variante: } 7-10 \\
\text { Jogadores }\end{array}$ \\
\hline 9) Ação Obrigatória* & 9) 3 - 6 Jogadores & 9) Contestações & 17) Avaliação Pessoal & 18) Ficha Técnica \\
\hline 10) Contestação & $\begin{array}{c}\text { 10) Ações de } \\
\text { Personagem/2 }\end{array}$ & 10) Exemplo (Gameplay) & - & - \\
\hline 11) Exemplo (Gameplay) & $\begin{array}{l}\text { 11) Variante: } \\
\text { Inquisidor* }\end{array}$ & 11) Contestações/2 & - & - \\
\hline- & 12) Ações Gerais/2 & 12) Ação Obrigatória* & - & - \\
\hline- & 13) Ação Obrigatória & 13) Variante: Inquisidor & - & - \\
\hline- & $\begin{array}{l}\text { 14) Exemplo } \\
\text { (Gameplay) }\end{array}$ & 14) Avaliação Pessoal & - & - \\
\hline
\end{tabular}

Tabela 2 - Tabela comparativa entre as características dos Vídeo tutoriais do jogo Coup

Dentre os vídeos analisados, o do canal "Romir Playhouse" foi o mais técnico e completo, além de ser o único que possui timestamp - mesmo que rudimentar - e não apresenta equívocos sobre as regras - indicados por asteriscos, na tabela. Todas essas diferenças parecem ser explicadas pelas variadas propostas dos canais, que produzem conteúdo independente da empresa produtora do jogo, não passando pelo mesmo crivo técnico ao qual o manual escrito, teoricamente, foi submetido.

Já o manual, além de não possuir índex, apresenta ilustrações insuficientes que contextualizam poucas informações textuais. Elas não explicam o setup do jogo, tampouco exemplificam jogadas, somente identificam os personagens das cartas.

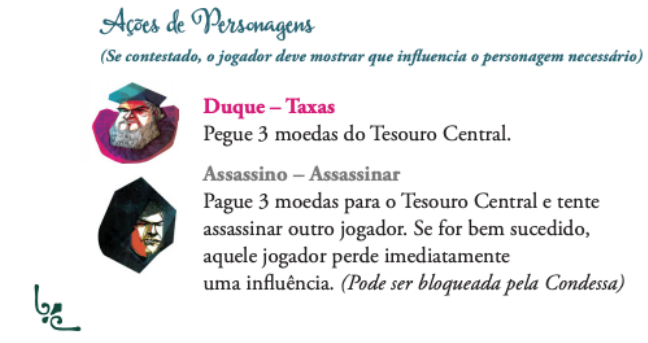

Figura 6 - Excerto do manual de Coup, apresentando o único tipo de imagens disponíveis: a ilustração dos personagens.

Coup apresenta alguns manuais auxiliares e fichasresumo para o jogo, que possuem versões resumidas das regras. Entretanto, as informações de uma das expansões, "A Reforma", não está presente no manual principal, somente no manual auxiliar desta edição, o que fica evidente na tabela comparativa dos manuais, a seguir: 


\begin{tabular}{|c|c|c|c|c|}
\hline \multicolumn{5}{|c|}{ Manuais Impressos - Coup } \\
\hline \multicolumn{2}{|c|}{ Manual Principal } & Ficha Resumo & Carta Expansão & Ficha da Corte \\
\hline \multicolumn{5}{|c|}{ Ficha Técnica } \\
\hline \multicolumn{2}{|c|}{ Português } & Português & Português & Português \\
\hline \multicolumn{2}{|c|}{ Sem Índex } & Sem índex & Sem índex & Sem índex \\
\hline \multicolumn{2}{|c|}{8 páginas } & 2 páginas & 1 página & 2 páginas \\
\hline \multicolumn{2}{|c|}{ Técnico/Oficial } & Técnico/Oficial & Técnico/Oficial & Técnico/Oficial \\
\hline \multicolumn{5}{|c|}{ Ordem das Informações } \\
\hline 1) Contextualização & 2) Componentes & 1) Ações & 1) Contextualização & 1) 3 - 6 Jogadores \\
\hline 3) Preparação & 4) Objetivo & $\begin{array}{l}\text { 2) Condição Ação } \\
\text { Obrigatória }\end{array}$ & $\begin{array}{l}\text { 2) Mudanças na } \\
\text { Preparação }\end{array}$ & $\begin{array}{c}\text { 2) } 3 \text { - } 6 \text { Jogadores } \\
\text { (variante) }\end{array}$ \\
\hline 5) Cartas & 6) Regras do Jogo & 3) Ações de Personagem & $\begin{array}{l}\text { 3) Mudanças na } \\
\text { Jogabilidade }\end{array}$ & 3) 7 - 8 Jogadores \\
\hline 7) Ações & 8) Ações Obrigatórias & 4) Variantes & 4) Novas Ações & 4) 9 - 10 Jogadores \\
\hline 9) Ações Gerais & 10) Ações de Personagem & - & 5) Créditos & - \\
\hline 11) Ações Contrárias & 12) Contestações & - & - & - \\
\hline 13) Interação entre Regras & 14) Exemplos & - & - & - \\
\hline 15) Variante: 2 Jogadores & 16) Variante: Inquisidor & - & - & - \\
\hline 17) Variante: 6+ Jogadores & 18) Créditos & - & - & - \\
\hline
\end{tabular}

Tabela 2 - Tabela comparativa entre as características dos Vídeo tutoriais do jogo Coup

Comparando ambas as tabelas, fica evidente que quase nenhum dos documentos seguem à risca as diretrizes levantadas neste artigo, sendo a principal questão a apresentação da "preparação" do jogo antes do "objetivo". A única exceção é o canal de Rafael Studart, porém ele comete pequenos equívocos sobre os poderes das cartas, não explicando precisamente o efeito do Embaixador; e sobre a ação obrigatória, não identificando que a ação obrigatória é aplicada com 10 ou mais fichas.

O manual oficial também apresenta a preparação do jogo antes do objetivo, mas não comete equívocos, da mesma forma que os manuais auxiliares não possuem erros. A presença desses manuais costuma facilitar que as regras sejam checadas pelos jogadores durante as partidas, sem haver a necessidade de folhear o manual inteiro. Entretanto, algumas das informações somente estão nos manuais auxiliares, o que não é adequado. Além disso, a seção do manual principal que explica o Inquisidor, personagem extra introduzido posteriormente, não possui ilustração do mesmo, ignorando a linguagem estabelecida anteriormente para os demais personagens.

$$
\text { Variante: O enquisidor }
$$

Remova todas as 3 cartas de Embaixador do Baralho da Corte e substitua por 3 cartas de Inquisidor.

O Inquisidor tem as seguintes açóes de personagem, mas apenas uma pode ser usada por turno:

Trocar - Troca uma carta com a Corte. Primeiro pegue uma carta aleatória do

Corte e escolha qual de suas cartas viradas para baixo deseja trocar

Corer trocar. Em seguida devolva uma carta para o Baralho do Corte.

Investigar - Olha uma carta de um adversário e pode forçar uma troca. Primeiro o adversário selecionado escolhe uma das suas cartas viradas para baixo para mostrar para o Inquisidor. O Inquisidor olha esta carta e pode entregá-la de volta, ou forçar o adversário a pegar uma nova carta aleatoriamente do Baralho da Corte, antes de devolvê-la.

Como uma açáo contrária, o Inquisidor pode bloquear Extorsáo.

Figura 7 - Excerto do manual de Coup sem ilustração para o personagem de uma das expansões.

\subsection{Nemesis-editoras Rebel e Awakened Realms}

Considerando que só há um vídeo oficial para este jogo, não foi necessário fazer pré-seleção. Na primeira publicação desse artigo ${ }^{9}$, o vídeo foi comparado com o manual do protótipo - disponibilizado publicamente durante as atualizações da campanha de financiamento coletivo do jogo - visto que ele foi o único documento escrito oficial encontrado na internet. Entretanto,

\footnotetext{
${ }^{9}$ Proceedings do $17^{\circ}$ Ergodesign \& USIHC, 2019.
} 
durante a edição desta versão, foi encontrado o manual da versão final do jogo, que foi incluído na tabela comparativa.

Uma breve leitura de ambos os documentos demonstra como o processo de teste com o público antes da revisão final é essencial para determinar o bom funcionamento do manual, que progrediu consideravelmente, se aproximando mais das diretrizes aqui levantadas na versão final.

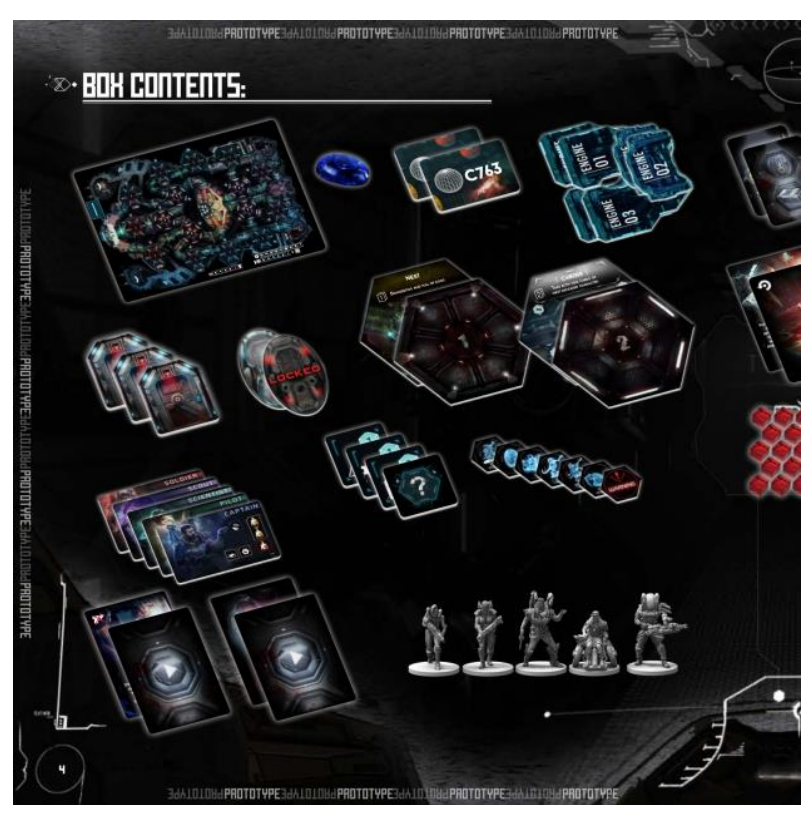

Figura 8 - Página 4 do manual protótipo do jogo Nemesis.

A escolha pelo uso de imagens que estão divididas em mais de uma página pode gerar grandes problemas para a decodificação das informações, visto que a maioria dos processos de encadernação acarretam alguma perda de área gráfica nas bordas do papel mais próximas do "miolo" do livreto, além de a presença de grampos poder obstruir partes essenciais das imagens, causando constrangimentos desnecessários aos usuários.

Ademais, as imagens selecionadas para ilustrar os componentes do jogo aparecem desacompanhadas dos textos. Considerando que, de acordo com Macklin (2015), o principal papel das ilustrações em manuais é contextualizar visualmente as informações descritas pelo texto, não considera-se adequado que somente as ilustrações sejam suficientes para apresentar os componentes usados no jogo, devendo ser sempre precedidas de texto.

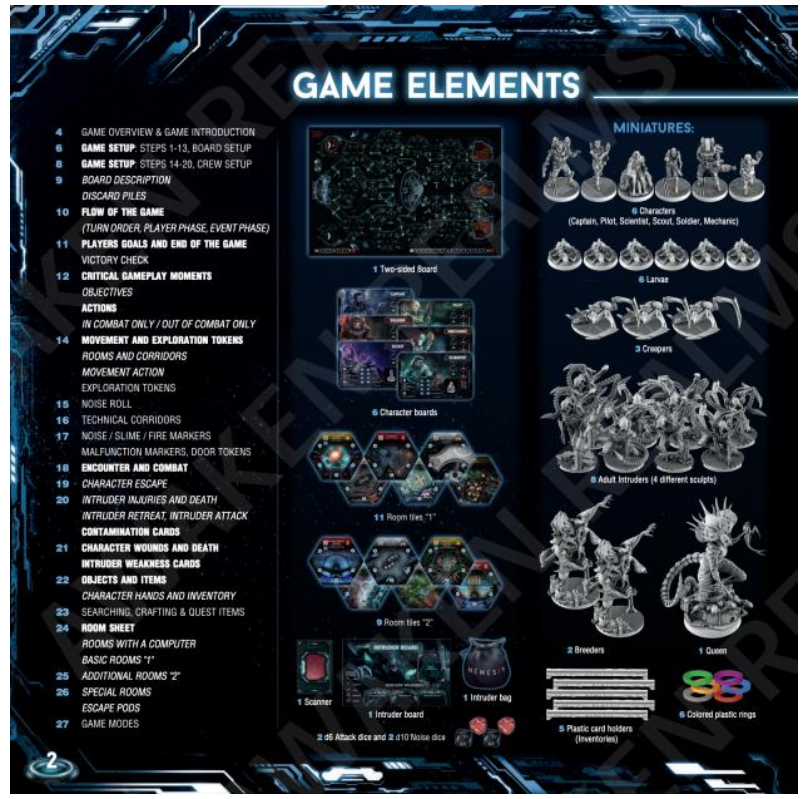

Figura 9 - Página 2 do manual final do jogo Nemesis.

Na versão final do manual, mesmo em primeira análise, pode-se perceber uma série de mudanças cruciais para o bom funcionamento do manual: a incorporação de um índice de paginação, inexistente no protótipo; o uso de ilustrações sem perspectiva isométrica, economizando espaço na página; ilustrações dos componentes acompanhadas de textos informativos sobre o que representam em jogo; substituição do título "Box Contents" (Conteúdo da Caixa) por "Game Elements" (Elementos do Jogo), que passa a fazer referência não às mídias físicas, mas ao contexto de jogo - contribuindo, mesmo que minimamente, para a imersão dos usuários.

A inserção de paratextos contextualizadores é uma das grandes mudanças entre as duas versões do manual, com o final possuindo a página 3 dedicada a notas do autor e visão geral e a página 4 dedicada a uma introdução detalhada da história retratada durante o jogo. Já a ordenação das categorias de informação parece se manter a mesma, em vias gerais, com a exceção do objetivo, que no protótipo aparece depois da preparação do jogo e no manual final é colocado após a explicação do funcionamento dos turnos. Algumas categorias tiveram seus nomes trocados, o que é normal, visto que muitas regras costumam ser revistas, atualizadas ou balanceadas durante $o$ momento de protótipo, mas tendem a seguir uma ordem coerente em ambos os casos. 


\begin{tabular}{|c|c|c|c|c|c|}
\hline \multicolumn{4}{|c|}{ Manuais Impressos } & \multirow{2}{*}{\multicolumn{2}{|c|}{$\frac{\text { Vídeo Tutorial }}{\text { Nemesis - How To Play }}$}} \\
\hline \multicolumn{2}{|c|}{ Manual Principal - Protótipo } & \multicolumn{2}{|c|}{ Manual Principal - Final } & & \\
\hline \multicolumn{6}{|c|}{ Ficha Técnica } \\
\hline \multicolumn{2}{|c|}{ Inglês } & \multicolumn{2}{|c|}{ Inglês } & \multicolumn{2}{|c|}{ Inglês } \\
\hline \multicolumn{2}{|c|}{ Sem Índex } & \multicolumn{2}{|c|}{ Com Índex } & \multicolumn{2}{|c|}{ Com Time Stamp } \\
\hline \multicolumn{2}{|c|}{24 páginas (4 em branco) } & \multicolumn{2}{|c|}{28 páginas } & \multicolumn{2}{|c|}{$50 ' 03 "$} \\
\hline \multicolumn{2}{|c|}{ Técnico/Oficial } & \multicolumn{2}{|c|}{ Técnico/Oficial } & \multicolumn{2}{|c|}{ Técnico/Oficial } \\
\hline \multicolumn{6}{|c|}{ Ordem das Informações } \\
\hline 1) Capa & 2) Componentes & 1) Capa & 2) Índice & 1) Contextualização & 2) Preparação \\
\hline 3) Preparação & 4) Objetivo do Jogo & 3) Componentes & 4) Visão Geral & 3) Glossário & 4) Fase do Jogador \\
\hline 5) Turno & $\begin{array}{c}\text { 6) Passo do Turno do } \\
\text { Jogador }\end{array}$ & 5) Créditos & 6) Notas do Autor & $\begin{array}{l}\text { 5) Passo do Turno do } \\
\text { Jogador }\end{array}$ & $\begin{array}{l}\text { 6) Passo das Ações } \\
\text { do Jogador }\end{array}$ \\
\hline 7) Ações Básicas & 8) Ações Especiais & 7) Contextualização & 8) Preparação & $\begin{array}{c}\text { 7) Passo da } \\
\text { Passagem de Turno }\end{array}$ & 8) Eventos \\
\hline 9) Ações de Sala & $\begin{array}{l}\text { 10) Fase da } \\
\text { Exploração }\end{array}$ & 9) Ordem dos Turnos & $\begin{array}{l}\text { 10) Passo do Turno } \\
\text { do Jogador }\end{array}$ & $\begin{array}{c}\text { 9) Passo da Faixa de } \\
\text { Tempo }\end{array}$ & $\begin{array}{l}\text { 10) Passo do } \\
\text { Ataque do Intruso }\end{array}$ \\
\hline $\begin{array}{l}\text { 11) Rolagem de } \\
\text { Sons }\end{array}$ & 12) Intrusos & 11) Passo do Evento & $\begin{array}{l}\text { 12) Objetivo do } \\
\text { Jogo }\end{array}$ & 11) Dano por Fogo & $\begin{array}{l}\text { 12) Resolvendo } \\
\text { Cartas de Eventos }\end{array}$ \\
\hline 13) Eventos & 14) Regras Gerais & $\begin{array}{l}\text { 13) Condições de Fim } \\
\text { de Jogo }\end{array}$ & $\begin{array}{l}\text { 14) Eventos } \\
\text { Principais }\end{array}$ & $\begin{array}{l}\text { 13) Desenvolvimento } \\
\text { da Bolsa de Intruso }\end{array}$ & $\begin{array}{l}\text { 14) Condições de } \\
\text { Fim de Jogo }\end{array}$ \\
\hline 15) Portas & 16) Reparos & $\begin{array}{l}\text { 15) Objetivos } \\
\text { Individuais }\end{array}$ & 16) Ações & $\begin{array}{l}\text { 15) Marcador de } \\
\text { Tempo }\end{array}$ & $\begin{array}{l}\text { 16) Destruição da } \\
\text { Nave }\end{array}$ \\
\hline $\begin{array}{l}\text { 17) Ataque aos } \\
\text { Jogadores }\end{array}$ & 18) Fim do Jogo & $\begin{array}{l}\text { 17) Movimento e } \\
\text { Exploração }\end{array}$ & $\begin{array}{l}\text { 18) Encontros e } \\
\text { Combate }\end{array}$ & $\begin{array}{l}\text { 17) Último } \\
\text { Sobrevivente }\end{array}$ & $\begin{array}{l}\text { 18) Condições de } \\
\text { Vitória }\end{array}$ \\
\hline- & - & 19) Objetos e Itens & $\begin{array}{l}\text { 20) Detalhamento } \\
\text { das Salas do Jogo }\end{array}$ & $\begin{array}{l}\text { 19) Checagem do } \\
\text { Motor }\end{array}$ & $\begin{array}{l}\text { 20) Checagem das } \\
\text { Coordenadas }\end{array}$ \\
\hline- & - & 21) Modos de Jogo & $\begin{array}{c}\text { 22) Apêndice: } \\
\text { Regras Resumidas }\end{array}$ & $\begin{array}{l}\text { 21) Checagem da } \\
\text { Contaminação }\end{array}$ & $\begin{array}{l}\text { 22) Checagem dos } \\
\text { Objetivos }\end{array}$ \\
\hline
\end{tabular}

Tabela 3 - Tabela comparativa entre as características do Vídeo tutorial e Manuais do jogo Nemesis.

A opção por apresentar o objetivo após a preparação do jogo é especialmente inadequada neste jogo, considerando que o preparo demanda que os jogadores façam escolhas sobre as cartas que manterão, entre outras coisas. Dessa forma, ter conhecimento do objetivos do jogo de antemão é essencial para tomar essa decisão, visto que ela impacta o desenrolar da partida.

No vídeo deste jogo, produzido pelo canal Board Game Replay ${ }^{10}$ as imagens representam quase exclusivamente o conteúdo e tabuleiro do jogo. Quando figuras humanas são mostradas, somente as mãos ficam visíveis - sempre interagindo diretamente com os componentes, cumprindo o papel que um computador faria em jogos digitais (LÉSTE, MONT'ALVÃO, CARVALHO, 2019).

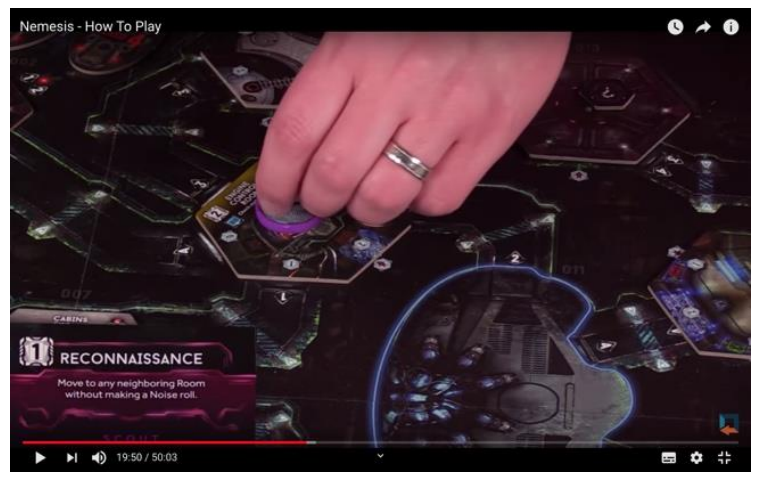

\footnotetext{
${ }^{10}$ Disponível em: https://www.youtube.com/user
} /boardgamereplay/featured Acesso 11 set, 2019. 
Figura 10 - Trecho do vídeo tutorial de Nemesis. Em comparação com os demais vídeos do mesmo canal, percebe-se uma clara discrepância tanto na escolha do enquadramento quanto no discurso adotado. Enquanto os vídeos comuns tem maior foco no gameplay e na interação entre as pessoas, este apresenta a figura humana como instrumento de interação com o tabuleiro e demais componentes do jogo, além de uma linguagem neutra, técnica e mais explicativa.

\subsection{Santorini-editoras Spin Master, Roxley e Galápagos Jogos}

Foram analisadas as versões mais atuais dos manuais disponíveis online, tanto em português quanto em inglês, além de um total de 3 vídeos: um sobre a campanha de kickstarter do jogo, onde as regras são explicadas; um sobre a expansão do velocino dourado (indisponível no Brasil); e um sobre uma das cartas de divindades: Europa \& Taulus. Entretanto, foram assistidos outros 6 vídeos sobre cartas de divindades, de forma que houvesse pelo menos uma carta representativa por cada grupo ${ }^{11}$ de divindades: (1) Cartas que podem ser usadas indiscriminadamente; (2) Cartas que só podem ser usadas em partidas de 2 ou 3 jogadores; (3) Cartas que só podem ser usadas em partidas de 2 jogadores; (4) Cartas que não podem ser usadas com a expansão do velocino dourado; (5) Cartas que não podem ser usadas em conjunto com outras cartas específicas; (6) Cartas de divindades avançados; (7) Cartas de divindades do Velocino Dourado.

Alguns dos vídeos de tutorial das god cards não apresentam todas as informações presentes nos manuais, nunca mencionando quando determinados deuses ou deusas não podem ser usados nas variantes de 3 ou 4 jogadores. Nos manuais impressos (e em suas versões digitais), essa informação está presente por meio de ícones acima do nome das cartas dos deuses. Três exemplos de situações distintas podem ser observados a seguir na figura 11, que demonstra a diferença da Deusa Circe, que só pode ser usada em partidas com 2 jogadores, mas não pode ser usada na expansão do Velocino Dourado; do Deus Dionísio, que pode ser usado em partidas de 2 a 4 jogadores e na expansão do Velocino Dourado; e

\footnotetext{
${ }^{11}$ Uma carta de divindade pode fazer parte de mais de um grupo de cartas. Também não foi considerado o
}

do Deus Eros, que pode ser usado em partidas de 2 a 4 jogadores mas não na expansão do Velocino.

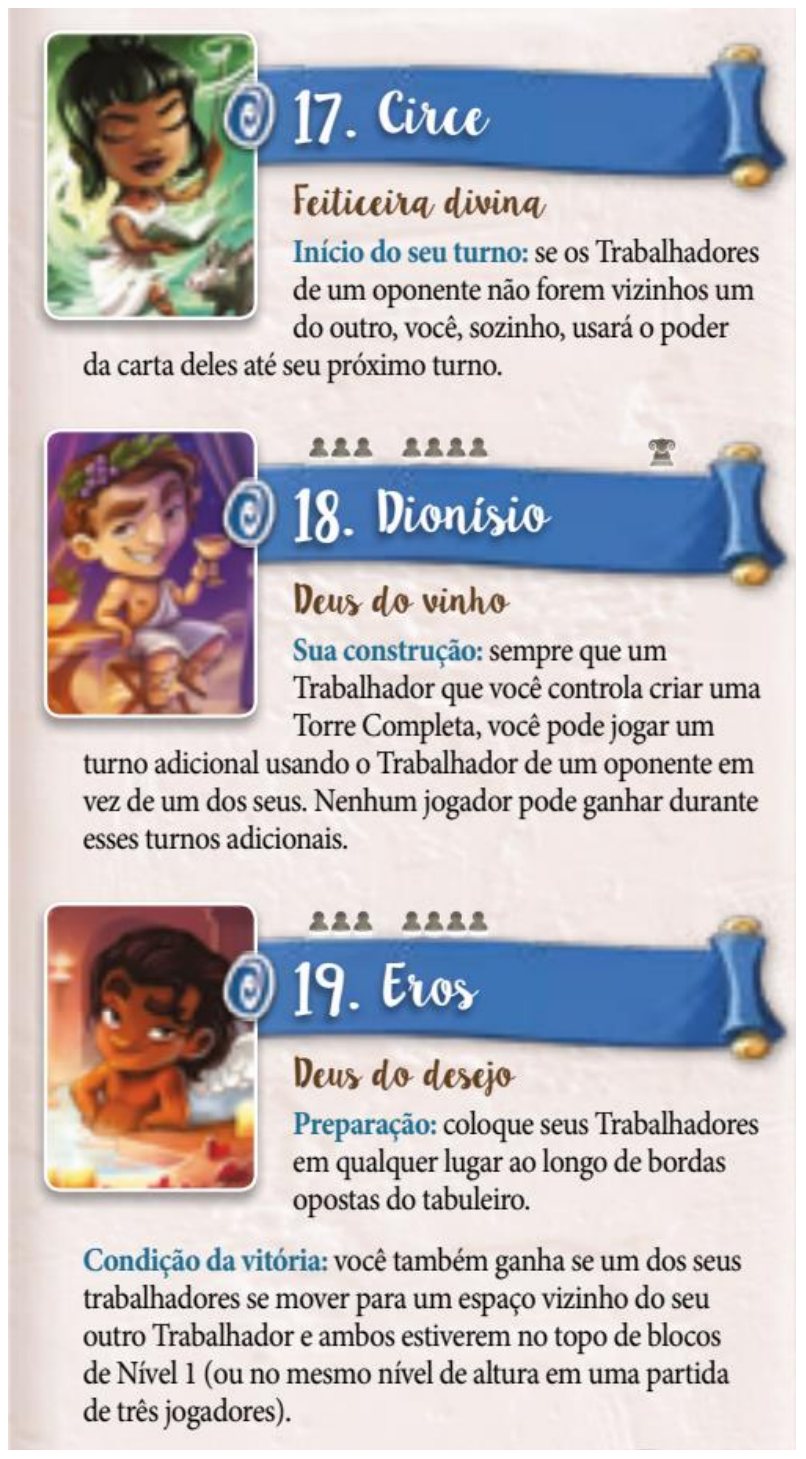

Figura 11 - Excerto do manual de regras do jogo Santorini mostrando 3 Divindades presente no jogo.

Essas informações estão descritas usando ícones acima da faixa com o nome da divindade. Na ausência de ícones, a divindade só pode ser usada em partidas regulares de dois jogadores; com o ícone de 3 figuras humanas aglomeradas, a divindade pode ser usada em partidas de 3 jogadores; com o ícone de 4 figuras, ela pode ser usada em partidas de 4 jogadores; e com o ícone do velocino, ela pode ser usada na expansão.

Nota-se que essa é uma das poucas informações presentes no manual escrito que não foi traduzida para o vídeo. Considerando que ela só está representada

grupo das Cartas de Heróis, visto que não há vídeos sobre elas. Acesso, 11 set. 2019. 
por meio de iconografia, em vez de texto escrito, talvez esse tenha sido o motivo para sua ausência, caso o texto do manual tenha sido usado como base para o roteiro dos vídeos.

Ademais, o manual impresso de Santorini, em ambos os idiomas, apresenta ilustrações adequadas para o jogo base, explicando a montagem do tabuleiro, movimentação das miniaturas, possibilidades de construção de estruturas, e condição de vitória do jogo:

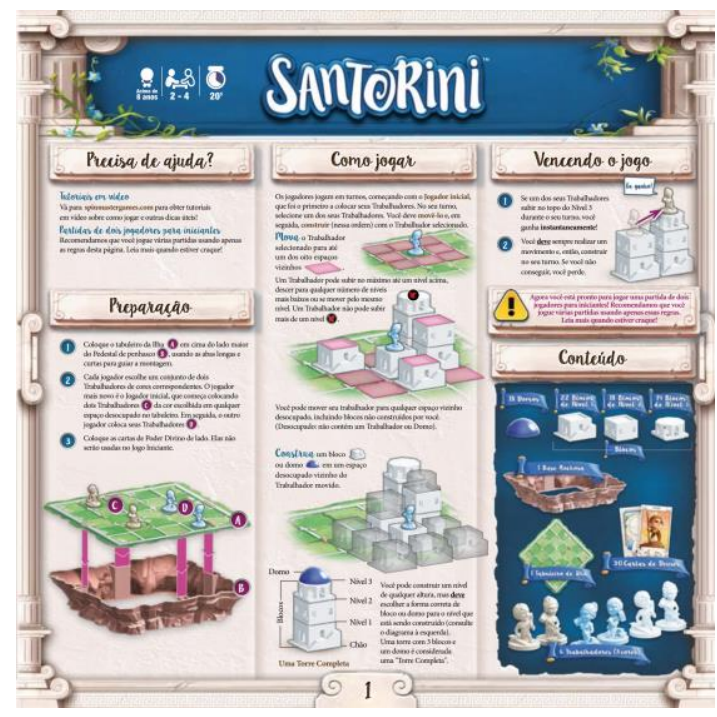

Figura 12 - Página 1 do manual de regras do jogo Santorini.

Em contrapartida, isso não se mantém nas demais páginas, onde os efeitos práticos das divindades não são exemplificados.

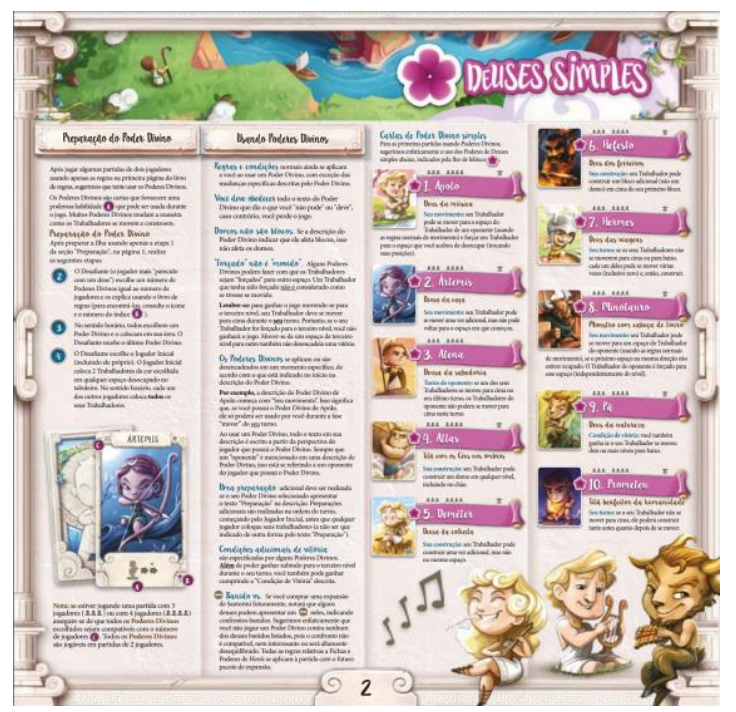

Figura 13 - Página 2 do manual de regras do jogo Santorini.
O canal que produz os vídeos tutoriais sobre o jogo, à primeira vista, parece mitigar essa situação ao explicar em detalhe os efeitos das cartas no jogo. A escolha de linguagem de animação 3D auxilia na explicação, por poder demonstrar explicitamente o efeito das cartas enquanto o áudio as explica, mantendo a mesma linha técnica do vídeo analisado no tópico 4.2.

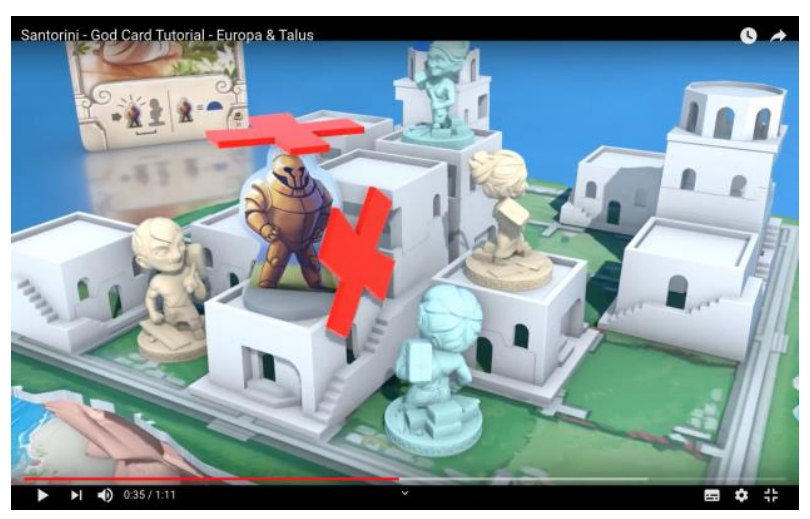

Figura 14 - Página 1 do manual de regras do jogo Santorini.

Porém mesmo com a grande quantidade de vídeos no canal, não há sobre todas as cartas - o que é um problema, caso essa fosse a fonte primária de acesso às regras. Ademais, o único vídeo que faz menção às regras base do jogo é o vídeo da campanha de financiamento coletivo do site Kickstarter, que somente o faz ao final do vídeo, não havendo menção disso no título - o que dificulta a busca e acesso a essa informação.

De um ponto de vista de produção, a formatação dos vídeos em pequenos trechos das regras, específicos para cada carta, permite que eles sejam produzidos gradativamente para novas expansões. Para manuais impressos, seria necessário revisar o manual anterior (tornando o anterior obsoleto) ou gerar um anexo (descentralizando as informações e interferindo na ordenação das informações na ordem em que se aplicam ao jogo) - e nenhuma das alternativas é ideal.

Sobre a ordenação das informações, cada documento apresenta uma ordem interna coerente com as diretrizes definidas aqui. Todavia, a descentralização completa de cada vídeo, que podem ser assistidos em qualquer ordem no YouTube, faz com que a apreensão de todas as informações pertinentes ao jogo não aconteça seguindo os mesmos critérios. 


\begin{tabular}{|c|c|c|c|c|c|}
\hline \multicolumn{3}{|c|}{ Manuais Impressos } & \multicolumn{3}{|c|}{ Vídeo Tutoriais (Título) } \\
\hline Manual Principal & \multicolumn{2}{|c|}{ Manual Principal } & $\begin{array}{l}\text { Original Santorini } \\
\text { Kickstarter Trailer }\end{array}$ & $\begin{array}{l}\text { Santorini - God } \\
\text { Card Tutorial - } \\
\text { Europa \& Talus* }\end{array}$ & $\begin{array}{l}\text { Santorini - Expansion } \\
\text { Tutorial - The Golden } \\
\text { Fleece }\end{array}$ \\
\hline \multicolumn{6}{|c|}{ Ficha Técnica } \\
\hline Português & \multicolumn{2}{|c|}{ Inglês } & Inglês & Inglês & Inglês \\
\hline Sem Índex & \multicolumn{2}{|c|}{ Sem Índex } & Sem Time Stamp & Sem Time Stamp & Sem Time Stamp \\
\hline 4 páginas & \multicolumn{2}{|c|}{6 páginas } & $04 ' 13 "$ & $01 ' 11^{\prime \prime}$ & $01 ' 03 "$ \\
\hline Técnico/Oficial & \multicolumn{2}{|c|}{ Técnico/Oficial } & Técnico/Oficial & Técnico/Oficial & Técnico/Oficial \\
\hline \multicolumn{6}{|c|}{ Ordem das Informações } \\
\hline 1) Dicas Iniciais & 1) Dicas Iniciais & 2) Preparação & 1) Contexto & 1) Contexto & 1) Contexto \\
\hline 2) Preparação & 3) Como Jogar & 4) Deuses Simples & 2) Turnos & $\begin{array}{l}\text { 2) Efeitos na } \\
\text { Preparação }\end{array}$ & $\begin{array}{l}\text { 2) Limitação de } \\
\text { Participantes }\end{array}$ \\
\hline 3) Como Jogar & $\begin{array}{l}\text { 5) Preparando } \\
\text { Poder Divino }\end{array}$ & $\begin{array}{l}\text { 6) Usando Poder } \\
\text { Divino }\end{array}$ & 3) Ações Gerais & 3) Poder da Carta & $\begin{array}{l}\text { 3) Efeitos na } \\
\text { Preparação }\end{array}$ \\
\hline 4) Deuses Simples & 7) Deuses Simples & 8) Deuses Avançados & $\begin{array}{l}\text { 4) Limitações das } \\
\text { Ações }\end{array}$ & $\begin{array}{l}\text { 4) Efeitos } \\
\text { Colaterais }\end{array}$ & $\begin{array}{l}\text { 4) Efeito dos Poderes } \\
\text { Divinos }\end{array}$ \\
\hline $\begin{array}{l}\text { 5) Preparando } \\
\text { Poder Divino }\end{array}$ & $\begin{array}{c}\text { 9) Deuses do } \\
\text { Velocino Dourado }\end{array}$ & $\begin{array}{l}\text { 10) Combinações } \\
\text { Proibidas }\end{array}$ & 5) Objetivo & $\begin{array}{l}\text { 5) Aplicação } \\
\text { prática }\end{array}$ & - \\
\hline $\begin{array}{l}\text { 6) Usando Poder } \\
\text { Divino }\end{array}$ & $\begin{array}{l}\text { 11) Deuses do } \\
\text { Velocino Dourado }\end{array}$ & $\begin{array}{l}\text { 12) Componentes do } \\
\text { Velocino Dourado }\end{array}$ & 6) Componentes & $\begin{array}{l}\text { 6) Efeitos } \\
\text { Negativos }\end{array}$ & - \\
\hline 7) Deuses Simples & $\begin{array}{c}\text { 13) Variante: } \\
\text { Velocino Dourado }\end{array}$ & $\begin{array}{c}\text { 14) Usando Poderes } \\
\text { de Heróis }\end{array}$ & 7) Cartas & - & - \\
\hline $\begin{array}{l}\text { 8) Deuses } \\
\text { Avançados }\end{array}$ & $\begin{array}{l}\text { 15) Cartas de } \\
\text { Heróis }\end{array}$ & $\begin{array}{l}\text { 16) Variante: } 3 \text { e } 4 \\
\text { jogadores }\end{array}$ & $\begin{array}{l}\text { 8) Objetivos da } \\
\text { Campanha }\end{array}$ & - & - \\
\hline $\begin{array}{l}\text { 9) Variante: } 3 \text { e } 4 \\
\text { jogadores }\end{array}$ & 17) Glossário & 18) Créditos & - & - & - \\
\hline 10) Glossário & - & - & - & - & - \\
\hline 11) Créditos & - & - & - & - & - \\
\hline
\end{tabular}

Tabela 4 - Tabela comparativa entre as características dos Vídeo tutoriais e Manuais do jogo Santorini.

Ainda, a escolha por vídeos descentralizados das cartas de divindades não foi acompanhada por nenhum conteúdo introdutório do uso dessas cartas de forma geral, que ocorre na página 2 do manual impresso (Figura 13).

\section{Conclusão e Próximos Passos}

Mesmo que a legislação brasileira indique a necessidade dos manuais de instruções de qualquer produto comercializado sejam didáticos, não há nenhuma regulamentação que indique o que, na prática, isso significa. Isto se reflete, entre outros fatores, na ausência de organização sistematizada das categorias de informações e de critérios comuns para os projetos gráficos dos manuais.

Em função disso, parece ter sido explorado o nicho de produção de vídeo tutoriais - que não está plenamente consolidado no Brasil, ainda apresentando algumas inadequações - na busca por sanar questões de usabilidade dos manuais.

Portanto, o presente artigo realizou uma pesquisa bibliográfica interdisciplinar em material das áreas de educação, ergonomia, psicologia e estudos lúdicos, 
para definir diretrizes que possam amenizar essa situação. Em sequência, foi realizada uma pesquisa documental para selecionar jogos sobre os quais existem vídeo tutoriais, para que essas diretrizes fossem aplicadas tanto aos manuais quanto aos vídeos em questão - considerando principalmente a ordenação das informações presentes neles.

Tendo isso em mente, é possível constatar que nenhum dos manuais apresentados anteriormente se adequa completamente à proposta de controle de qualidade da seção 3.1, seja por ordenação inadequada, falta de indexação, utilização insuficiente ou descontextualizada de imagens, ausência de informações completas, presença de informações erradas - ou, em casos mais graves, combinações desses fatores.

Paralelamente, os vídeo tutoriais não oficiais foram considerados, do ponto de vista da Ergonomia, muito mais precários em execução que os oficiais - os quais pareciam seguir roteiros e direções de arte mais coerentes e que consideravam a experiência dos usuários como fator determinante.

Desta forma, entende-se que o presente artigo atingiu todos os seus objetivos, ao apresentar uma proposta de diretrizes baseada em conceitos de campos do conhecimento complementares e pertinentes à questão - aplicando-a ao contexto real do mercado de jogos analógicos ao mensurar as características dos documentos selecionados.

Os resultados aqui apresentados, além de úteis para qualquer pesquisa que vise estudar a qualidade de manuais de jogos, são de fácil replicabilidade, dependendo somente da disponibilidade dos pesquisadores que pretendam realizar o estudo, e do acesso aos manuais, disponíveis nos repositórios aqui evidenciados.

Para dar sequência à pesquisa, considera-se pertinente reformular manuais presentes no mercado em função das diretrizes aqui apresentadas. Após a reformulação, devem ser realizados testes com usuários, a fim de medir se há impacto positivo no processo de apreensão, compreensão e aplicação das regras.

Caso haja, os jogadores terão se tornado mais competentes nas tarefas que pretendem desempenhar, em função do acesso facilitado às informações pertinentes ao contexto. Dessa forma, a verossimilhança interna do jogo estará mais protegida - o que, consequentemente, proporciona experiências mais proveitosas e positivas aos usuários, atingindo o objetivo principal de qualquer estudo ergonômico.

Por fim, é interessante considerar uma terceira modalidade de aprendizado das regras dos jogos: a monitoria presencial das ludotecas e eventos de jogos. Nessas situações, pessoas que conhecem os jogos os ensinam aos usuários e consumidores, que passam a não ter a necessidade de entrar em contato com o documento do manual, ao passo que recebem todos os estímulos audiovisuais que estariam presentes nos vídeos. Ainda há a vantagem de estarem interagindo diretamente com outro ser humano, havendo a possibilidade de tirar dúvidas e revisitar aspectos e informações da explicação que possam não ter sido satisfatoriamente apreendidos. Isso mitiga uma das principais críticas ao modelo de vídeo tutorial, onde há uma difícil navegação para a busca de informações, ao passo que é o modelo de mais difícil disponibilidade, considerando que é necessário estar na presença de um profissional que já conhece o jogo.

\section{Referências Bibliográficas}

BARON, R. A.; KALSHER, M. J. Psychology: From Science to Practice, Capítulo 6. Allyn \& Bacon, Boston, 2005.

BRASIL, [ANVISA], Resolução - RDC No 360 . 2003. Disponível em:

http://portal.anvisa.gov.br/documents/33880/2568070/ res0360_23_12_2003.pdf/5d4fc713-9c66-4512-b3c1afee57e7d9bc. Acesso em: 11 set. 2019.

BRASIL, [Ministério da Educação] Guia do Programa Nacional do Livro Didático. 2019. Disponível em:

https://pnld.nees.com.br/assetspnld/guias/Guia_pnld_2020_pnld2020-projetosintegradores-1.pdf. Acesso em: 13 set. 2019.

BRASIL. Lei nº. 8.078, de 11 de setembro de 1990. Código de Defesa do Consumidor. Dispõe sobre a proteção do consumidor e dá outras providências. Disponível em: https://www.planalto.gov.br/ccivil_03/Leis/L8078.htm Acesso em: 08 set. 2019. 
BRASIL. Edital de Convocação 01/2018 -

CGPLI Edital de Convocação para o Processo de Inscrição e Avaliação de Obras Didáticas e Literárias para o Programa Nacional do Livro e do Material Didático PNLD 2020. 2018.

Disponível em:

https://www.fnde.gov.br/programas/programas-dolivro/consultas/editais-programas-

livro/item/11555-edital-pnld-2020. Acesso: 17 mar. 2020.

BROADBENT, Donald Eric. Language and Ergonomics. Applied Ergonomics, Inglaterra, v. 8.1, p. 15-18, março 1977.

CARVALHO, M. C.; LÉSTE, J. V.; MONT'ALVÃO, C. Manuais de Jogos Enquanto Objetos Educativos: o desenvolvimento de estratégia em jogos analógicos como situações de aprendizado. SBGames, Education Track, V. 18, 2019. ISSN: $2179-2259$.

Disponível em: https://www.sbgames.org/ sbgames2019/files/papers/EducacaoShort/198400. pdf. Acesso: 30 mar. 2020.

CHAPANIS, Alphonse. Words Words Words. $\mathbf{8}^{\mathbf{0}}$ Encontro Anual da Human Factors Society. V. 7, n. 1, p. 1-17, Maryland, Estados Unidos da América, 1965.

\section{DUARTE, Luiz Cláudio Silveira. Traços}

Distintivos de Estratégias em Jogos. 2015.

Dissertação (Mestrado em Design) - Programa de Pós-Graduação em Design, Universidade Federal do Paraná, Paraná, 2015.

FRACALANZA, H.; NETO, J. M. O Livro Didático de Ciências: Problemas e Soluções. Ciência \& Educação (Bauru). Programa de PósGraduação em Educação para a Ciência, Universidade Estadual Paulista (UNESP), Faculdade de Ciências, campus de Bauru., v. 9, n. 2, p. 147-157, 2003.

FREITAS, N. K., RODRIGUES, M. H. O Livro

Didático ao Longo do Tempo: a forma do conteúdo. $\mathbf{1 8}^{\mathbf{0}}$ Seminário de Iniciação Científica. Universidade do Estado de Santa Catarina, 2008.
GAGNÉ, R. M. Como se Realiza a Aprendizagem.

$1^{a}$ Edição, Reimpressão. Rio de Janeiro: Ao Livro

Técnico S. A., 1973.

HAM, Ethan. Tabletop Game Design for Video Game Designers. Focal Press. Burlington, Boston, Estados Unidos da América, 2016.

HUIZINGA, Johan. Homo Ludens: o jogo como elemento da cultura. $8^{a}$ Edição. São Paulo:

Perspectiva, 2018

JARA, David. A Closer Look at the (Rule-) Books: Framings and Paratexts in Tabletop Role-playing Games. International Journal of Role-Playing, n. 4, University of Tampere, Finland, Abril, 2012.

\section{KURTZ, L. B. CARRION, R. C. A. Inception! A} Relação do Jogador com a Materialidade da Plataforma Tabletop Simulator. SBGames, Volume 17, p 948-951, Paraná, outubro 2018.

MACKLIN, Ryan. 11 Rules for Board Game Rules Writing. 6 fev, 2015. Disponível em:

http://ryanmacklin.com/2015/02/11-rules-board-gamewriting/. Acesso em: 10 set. 2019.

MORAES, A. Ergonomia e projeto de produtos, informação, interfaces da interação homemcomputador e espaços arquiteturais: ensino e pesquisa, XXIII Encontro Nac. de Eng. de Produção Ouro Preto, MG, Brasil, 2003.

TUFTE, Edward Rolf. The Visual Display of Quantitative Information. Graphics Press, Cheshire Connecticut, 1983.

UNGER, G. Legible? Emigre, n. 65, p. 100-111, 2003. Disponível em: https://www.emigre.com/Essays/Magazine/Legible. Acesso em: 10 set. 2019.

\subsection{Vídeo tutoriais assistidos}


PUC-Rio Pontifícia Universidade Católica do Rio de Janeiro Departamento de Artes \& Design | PPGDesign

LEUI | Laboratório de Ergodesign e Usabilidade de Interfaces

COUP - Como Jogar. [S. l.: s. n.], 2017. 1 video (19 min). Publicado pelo canal Romir Play House. Disponível em: https://www.youtube.com/watch? $\mathrm{v}=6 \mathrm{UpW} 8 \mathrm{dV} 2 \mathrm{Oks}$. Acesso em: 11 set. 2019.

COUP - Review por Jogando Offline (s02e01). [ $S$ l.: s. n.], 2014. 1 video (24 min). Publicado pelo canal Jogando Offline. Disponível em: https://www.youtube.com/watch?v=NB7rwNVHB go Acesso em: 11 set. 2019.

FOI GOLPE | Gigante Leo, Defante, Jhonny, Rosana e Ulisses Mattos jogam COUP | De Quem é a Vez? [S. l.: s. n.], 2019. 1 video (25 min) Publicado pelo canal Rafael Studart. Disponível em: https://www.youtube.com/watch ?v=bwbaMEPm1dY. Acesso em: 11 set. 2019.

JACK Explicador - Coup. [S. l.: s. n.], 2014. 1 video (33 min). Publicado pelo canal Meeple TV. Disponível em: https://www.youtube.com/watch? $\mathrm{v}=$ nwWCJdN32wA. Acesso em: 11 set. 2019.

LET'S Play COUP feat. Brennan Lee Mulligan from CollegeHumor | Overboard, Episode 12. [S. l.: s. n.], 2019. 1 video (30 min). Publicado pelo canal Polygon. Disponível em: https://www.youtube.com/watch?v=BrjCPnbEMfE . Acesso em: 11 set. 2019.

LOVE Letter \& Coup: Fine Brothers and Felicia Day Join Wil Wheaton. [S. l.: s. n.], 2015. 1 video (44 min). Publicado pelo canal Geek \& Sundry. Disponível em: https://www.youtube.com/watch?v=k2YUYPDq7g Q. Acesso em: 11 set. 2019.

NEMESIS - How To Play. [S. l.: s. n.], 2019. 1 video (50 min). Publicado pelo canal Board Game Replay. Disponível em: https://www.youtube.com/ watch?v=g1NnAHptaeE. Acesso em: 11 set. 2019.

ORIGINAL Santorini Kickstarter Campaign. [S. l.: s. $n$.], 2018. 1 video (4 min) Publicado pelo canal Roxley. Disponível em: https://www.youtube.com/watch?v=IBfGD8aq7Is \&. Acesso em: 13 set. 2019.
SANTORINI - Expansion Tutorial - The Golden Fleece. [S. l.: s. n.], 2016. 1 video (1 min) Publicado pelo canal Roxley. Disponível em:

https://www.youtube.com/watch? v=fKQSQCisWTI. Acesso em: 13 set. 2019.

SANTORINI - God Card Tutorial - Apollo. [S. l.: s. n.], 2016. 1 video (1 min) Publicado pelo canal Roxley. Disponível em: https://www.youtube.com/ watch?v=95EHcOSfwsY. Acesso em 13 set, 2019.

SANTORINI - God Card Tutorial - Bia. [S. l.: s. n.], 2016. 1 video (1 min) Publicado pelo canal Roxley. Disponível em: https://www.youtube.com/ watch? $v=r E N x F k F 04 a w$. Acesso em: 13 set. 2019.

SANTORINI- God Card Tutorial - Circe. [S. l.: s. n.], 2016. 1 video (1 min) Publicado pelo canal Roxley. Disponível em: https://www.youtube.com/ watch?v=Z7RY6w2wGt0. Acesso em: 13 set. 2019.

SANTORINI - God Card Tutorial - Europa \& Talus. [S. l.: s. n.], 2018. 1 video (1 min) Publicado pelo canal Roxley. Disponível em: https://www.youtube.com/watch? v=2gOzUefcL68. Acesso em: 13 set. 2019.

SANTORINI - God Card Tutorial - Gaia. [S. l.: s. n.], 2019. 1 video (1 min) Publicado pelo canal Roxley. Disponível em: https://www.youtube.com/ watch?v=9ufsYvR19Aw. Acesso em: 13 set. 2019.

\section{Agradecimentos}

O presente trabalho foi realizado com apoio da Coordenação de Aperfeiçoamento de Pessoal de Nível Superior - Brasil (CAPES) - Código de Financiamento 001.

Agradecimento especial a Júlia Martins N., que auxiliou na interpretação das legislações pertinentes e na revisão do presente artigo. 